\title{
A French Plot to Undermine Monetary Stability?
}

In a so-called Staff Position Note, a non-official document, the chief economist of the International Monetary Fund, Olivier Blanchard, and two coauthors have suggested that central banks should raise their medium-run inflation target from around two per cent to something like four per cent. This has raised quite a stir among central bankers, economists, government officials and the press. In Germany in particular the proposal has met with near universal rejection.

Blanchard, a French-born and US educated economist who taught at one of the leading American universities, the Massachusetts Institute of Technology, before coming to the IMF, is one of the most successful macroeconomists of our time. He is usually regarded as a Neo-Keynesian economist who, in contrast to the Chicago school and its adherants, does not believe that markets usually get it right when left alone and is in favour of active government policy in situations like the current crisis. Otherwise, of course, it would not make much sense for him to accept a position at an institution like the IMF. The argument he develops along with Giovanni dell' Ariccia and Paulo Mauro is quite simple. There is a natural barrier below which nominal interest rates cannot fall since they can not drop below zero (although some people have argued even that might be possible). In a situation in which inflation is low and interest rates are close to zero, central banks have little remaining leeway to make credit cheaper and more easily available and thus to jump-start an economy in recession.

In fact, the global financial crisis has left central banks struggling. They have resorted to "quantitative easing" and other creative methods, but it would have been much easier for them to conduct their usual business and lower interest rates, the argument goes. When inflation is higher than two per cent, nominal interest rates will be sufficiently high so that they can be lowered. A similar argument had been made by Nobel-prize winning economist Paul Krugman, who suggested in the wake of the Japanese deflation that the Bank of Japan create the expectation of inflation. By increasing inflation, it might then even be possible for real interest rates to become negative, which should be good for investment and real activity. It would also make consumption more attractive than saving and increase demand. Thus, Blanchard's idea is not all that new; what is new is the argument that two per cent inflation does not provide enough room to manoeuvre in a big crisis like the current one-and that it is coming from one of the most important institutions of the global economy. One can be sure that the paper had been cleared by managing director Dominique Strauss-Kahn.

Another positive side effect of increasing inflation is that governments find it easier to lower their debt. In times of low inflation, nominal government debt is usually not indexed to inflation, and thus an unexpected increase in inflation lowers the real value of the debt. Inflation is hence a time-honoured method to reduce public debt and a way to alleviate the headaches that ministers of finance will have in the next couple of years. Of course, should the idea take hold, investors will demand that government debt be indexed, but that would only apply to newly issued debt. The IMF's idea is thus certain to find at least tacit support among some government officials.

In Germany, however, with its history of hyperinflation some ninety years ago, the spectre of higher inflation is causing nightmares. Some people have speculated that the whole idea of a monetary union was a plot by other countries, in particular the so-called Club Med countries (among them Italy, France, Spain, Portugal and, yes, Greece), to undermine German monetary stability. They might get the idea that a French managing director and his 
chief economist have found yet another way to undermine the euro's stability. On the other hand, it is another Frenchman, Jean-Claude Trichet at the European Central Bank, who is defending its current inflation target of two per cent.

Conspiracy theories aside, Blanchard's paper discusses the use of available instruments for macroeconomic management in general. It makes some interesting and thoughtful observations about how macroeconomic and regulatory thinking developed in the wrong direction before the crisis, how the trust in markets failed, and what steps must be taken to right the direction of economic policy. The revised inflation target is only one aspect in a much broader attack on past and current policy mistakes, in particular with regard to fiscal and regulatory policy. The authors' main point is that macroeconomic policy needs more room to manoeuvre in times of crisis. This includes not only monetary policy but also a more strongly anticyclical fiscal policy. Blanchard and his co-authors suggest that fiscal policy should develop more room for expansion in crises by being much tighter in normal times. They argue that the fiscal response to the crisis was too weak because fiscal policy before the crisis was too expansive. The authors also argue that automatic stabilisers of a different kind are needed, such as tax rebates for lower incomes that kick in once a certain threshold in the macro data is exceeded. The latter assertion is certain to be controversial as well. However, the contention that fiscal policy should be tighter in normal times is in line with the Maastricht strategy of the European Union and should be welcomed even by those who reject the monetary policy part of the package, such as Bundesbank president Axel Weber. When looking at the whole paper, it is hard to understand why it has become so controversial. This can probably only be explained by German inflation phobia. In fact, some observers take the fact that the Bundesbank rejected the idea as evidence that it must be right.

There is a danger, though, in changing the official inflation target. It is likely that a changed target would give rise to a period of higher uncertainty. A natural reaction would be for people to ask why they shouldn't expect six or eight per cent inflation, requiring accordingly higher risk premiums. Hence, establishing a credible target of four per cent would be accompanied by a more or less extended period of higher nominal interest rates. Indeed, it is quite likely that inflationary expectations will be going up anyway, given the public debt developments in most countries. The temptation to use inflation to lower real debt and to inflate away part of the demographic burden in Europe will increase in the coming decades. Adjusting inflation targets now might then be perceived as just a first step in a series of upward adjustments. This in turn could also affect the external position of the euro, increasing inflation further.

And of course this would not be in the interests of the German economy. Not only would German savings be affected; it might also undermine the external competitiveness of German products. Germany's competitive advantage since the introduction of the euro has been due to its very modest wage developments, which boosted exports and increased the number of jobs. This was possible because of strongly increasing nominal wages in other regions of Europe which, given low inflation, increased real wages there. This loss of competitiveness can no longer be regained by devaluation, but a simpler solution might be to have real wages decline due to higher inflation. So, surely, the German position will be to fight tooth and nail against an increase in the inflation target, and it will be joined in this fight by the ECB, even more so if Axel Weber succeeds current ECB president Trichet, as is widely rumoured. There is therefore little reason to fear a revision of the inflation target at the moment; nonetheless, the paper by Blanchard, dell' Ariccia and Mauro should be taken seriously for the other points it raises. 